\title{
Exaggerated secretion of glucagon-like peptide-1 (GLP-1) could cause reactive hypoglycaemia
}

\author{
M. Toft-Nielsen ${ }^{1,2}$, S. Madsbad ${ }^{1}$, J. J. Holst ${ }^{2}$ \\ ${ }^{1}$ Department of Endocrinology, Hvidovre Hospital, University of Copenhagen, Denmark \\ ${ }^{2}$ Department of Medical Physiology, Panum Institute, University of Copenhagen, Denmark
}

Summary The plasma concentrations of the insulinotropic incretin hormone, glucagon-like peptide-1 (GLP-1) are abnormally high after oral glucose in partially gastrectomised subjects with reactive hypoglycaemia, suggesting a causal relationship. Because of the glucose-dependency of its effects, it is impossible to induce hypoglycaemia in normal subjects in the basal state by exogenous GLP-1, regardless of dose. To further assess the role of the incretin hormones in reactive hypoglycaemia, we reproduced the glucose and hormone profiles of the patients with reactive hypoglycaemia in 8 healthy volunteers in 4 separate protocols: 1) i.v. infusion of glucose (25 g) alone, 2) glucose together with i.v. GLP-1 infusion, and 3) and 4) glucose together with i.v. infusion of the other incretin hormone, glucose-dependent insulinotropic polypeptide (GIP), at two different infusion rates. The plasma glucose, GLP-1 and GIP concentrations (low dose) obtained were comparable with those of the patients. With GLP-1, infusion of a total of $33.4 \pm 1.3 \mathrm{~g}$ glucose was required to obtain plasma glucose concentrations similar to those obtained by glucose infusion alone; with low GIP, $28.0 \pm 1.2 \mathrm{~g}$ and with high GIP $38.4 \pm 3.5 \mathrm{~g}$. Insulin concentrations increased 10-fold with GLP-1 compared with i.v. glucose alone, but less with high and low GIP. In contrast, C-peptide concentrations were similar after GLP-1 and high GIP. After termination of i.v. glucose the lowest glucose concentrations were 4.5 (3.7-4.9) (median, range) for glucose alone; $2.4(1.9-2.8) \mathrm{mmol} / 1$ with GLP-1; 3.7 (2.6-4.0) with low GIP and 3.3 (2.1-4.2) with high GIP. Thus, the exaggerated GLP-1 response to nutrients in patients with accelerated gastric emptying could be responsible for their high incidence of postprandial reactive hypoglycaemia. [Diabetologia (1998) 41: 1180-1186]

Keywords Late dumping, gastrectomy, glucose dependent insulinotropic peptide (GIP), insulin, glucagon.
Postprandial symptoms, known as the dumping syndrome, often complicate total or partial gastrectomy and can be classified as "early" or "late" dumping [1, 2,3 ] according to the temporal relation to the preceding meal. Early symptoms consist of neurovascular

Received: 23 February 1998 and in revised form: 18 May 1998

Corresponding author: J. J. Holst, MD, Department of Medical Physiology, The Panum Institute, University of Copenhagen, Blegdamsvej 3, DK-2200 Copenhagen NV, Denmark Abbreviations: GLP-1, Glucagon-like peptide-1; GIP, gastric inhibitory hormone or glucose-dependent insulinotropic hormone; ANOVA, analysis of variance; OGTT, oral glucose tolerance test. and gastrointestinal symptoms appearing within 30 min after eating, while the late symptoms (sweating, paleness, fatigue, muscular weakness, blurred consciousness, anxiety, tremor, tachycardia) appear after $2 \mathrm{~h}$ or later and are related to hypoglycaemia. After test meals or oral glucose tolerance tests, gastrectomised patients show rapid gastric emptying and increased intestinal motility $[4,5,6,7]$ which are thought to be responsible for the quick and steep rise in plasma glucose concentration. At first, the abnormal hyperglycaemic response itself was thought to be responsible for the pronounced concomitant hyperinsulinaemia seen in these patients [1] but similar plasma glucose concentrations obtained by i.v. glucose infusion do not induce equally high insulin and 
are not followed by hypoglycaemia [2, 8]. It was therefore proposed that excessive secretion of insulinotropic (gut) hormones $[2,8,9]$ stimulated by rapid entry of nutrients into the intestine, might explain the hyperinsulinaemia. The hyperinsulinaemia, in turn, would be responsible for a delayed, reactive hypoglycaemia [1, 2]. Indeed, in recent studies, plasma concentrations of the insulinotropic gut hormone, glucagon-like peptide-1 (GLP-1), increased up to 10fold after oral glucose compared with matched control subjects $[10,11,12]$ whereas plasma concentrations of the other important incretin hormone, glucose-dependent insulinotropic polypeptide (GIP) were either similar [13] or slightly raised $[14,15,16]$. Supporting a pathogenetic role for GLP-1, its secretion has been shown to correlate with the rate of gastric emptying, the secretion of insulin and the severity of the reactive hypoglycaemia $[10,17,18]$. On the other hand, it is impossible to induce hypoglycaemia in normal subjects in the basal state by infusion of GLP-1 [19] or GIP [20] because their insulinotropic action is glucose-dependent and is weak or absent at normal basal state glucose concentrations.

To further assess the possible role of GLP-1 and GIP in reactive hypoglycaemia, we performed experiments in normal volunteers aiming at copying, by i. v. infusion, the concentrations of glucose and GLP1 and GIP, respectively, as measured in patients with reactive hypoglycaemia after partial gastrectomy.

\section{Methods}

Subjects. We studied 8 healthy volunteers (6 men, 2 women; mean age: 24 years, range: 20 to 28 ; mean body mass index: 22 $\mathrm{kg} / \mathrm{m}^{2}$, range: 21 to 23 ) who were instructed to maintain a carbohydrate-rich diet of no less than $10500 \mathrm{~kJ}$, containing primarily complex carbohydrates, for 3 days prior to the experiments. All were students with no personal or family history of diabetes mellitus and none was taking medicine. All agreed to participate after oral and written information. The study was approved by the ethical committee for Copenhagen and Frederiksberg Municipalities, dated 22nd August 1994 and 17th March 1995, respectively, j. nos. KF 01-177/94 and KF $01-087 / 95$.

Infusion protocol. GLP-1: Synthetic human GLP1(7-36amide) of GMP grade (Cat. no. PGAS242) was purchased from Saxon, Haan, Germany (subsidiary of Bachem, California). The peptide was dissolved in $0.9 \%$ saline containing $1 \%$ human serum albumin (Albumin Nordisk, Novo Nordisk, Bagsvaerd, Denmark, guaranteed to be free of hepatitisB surface antigen and human immunodeficiency virus antibodies), subjected to sterile filtration, dispensed in appropriate amounts into glass ampoules and stored frozen under sterile conditions until the day of the experiment.

GIP: Synthetic human GIP (cat. no. PGAS125) was also purchased from Saxon and prepared as described for GLP-1.

Infusion protocols (Fig. 1): All subjects received an i.v. infusion of $25 \mathrm{~g}$ glucose ( $20 \%$ solution) over $30 \mathrm{~min}$ on the first day (protocol A). The plasma glucose curve for the first $30 \mathrm{~min}$ for each individual in protocol A was copied in the

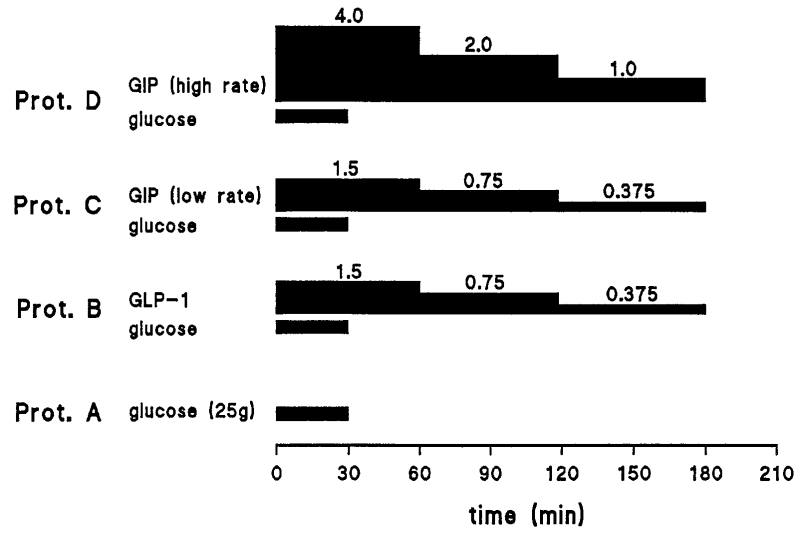

Fig. 1. Infusion protocols. Glucose infusion rate was adjusted in protocol B, C, and D to copy glucose concentrations obtained in protocol A. GLP-1 and GIP infusion rates are in $\mathrm{pmol} \cdot \mathrm{kg}^{-1} \cdot \min ^{-1}$

three following, randomised experiments with additional 3-h i.v. hormone infusions - namely, protocol B: GLP-1 (1.5 $\mathrm{pmol} \cdot \mathrm{kg}^{-1} \cdot \mathrm{min}^{-1}$ for $60 \mathrm{~min}, 0.75 \mathrm{pmol} \cdot \mathrm{kg}^{-1} \cdot \mathrm{min}^{-1}$ for $60 \mathrm{~min}$ and $0.375 \mathrm{pmol} \cdot \mathrm{kg}^{-1} \cdot \mathrm{min}^{-1}$ for $\left.60 \mathrm{~min}\right)$, protocol $\mathrm{C}$ : low GIP (1.5 $\mathrm{pmol} \cdot \mathrm{kg}^{-1} \cdot \mathrm{min}^{-1}$ for $60 \mathrm{~min}, \quad 0.75$ $\mathrm{pmol} \cdot \mathrm{kg}^{-1} \cdot \mathrm{min}^{-1}$ for $60 \mathrm{~min}$ and $0.375 \mathrm{pmol} \cdot \mathrm{kg}^{-1} \cdot \mathrm{min}^{-1}$ for $60 \mathrm{~min})$, and protocol D: high GIP $\left(4.0 \mathrm{pmol} \cdot \mathrm{kg}^{-1} \cdot \mathrm{min}^{-1}\right.$ for $60 \mathrm{~min}, \quad 2.0 \mathrm{pmol} \cdot \mathrm{kg}^{-1} \cdot \mathrm{min}^{-1}$ for $60 \mathrm{~min}$ and 1.0 $\mathrm{pmol} \cdot \mathrm{kg}^{-1} \cdot \mathrm{min}^{-1}$ for $\left.60 \mathrm{~min}\right)$. The experiments were stopped 30 min after termination of the infusions. The subjects were recumbent with indwelling cannulas inserted into forearm or cubital veins in both arms: one for infusion of glucose and hormones, and one for blood sampling. Electrocardiogram was monitored throughout the experiments. Blood was drawn at time $-15,0,15,30,60,90,120,150,180$, and $210 \mathrm{~min}$ for analysis of plasma insulin, glucagon, GLP-1, and GIP. Plasma glucose was measured every $5 \mathrm{~min}$ during the glucose infusion (time 0 to $30 \mathrm{~min}$ ), thereafter every $10 \mathrm{~min}$ and, during hypoglycaemia, every $2^{1} / 2 \mathrm{~min}$. Blood was distributed into fluoride tubes for plasma glucose and into EDTA tubes $(6 \mathrm{mmol} / \mathrm{l}$; Merck, Darmstadt, Germany) with aprotinin (500 KIU/ml blood; Trasylol, Bayer, Leverkusen, Germany) for peptide analyses. Tubes were chilled immediately in ice and centrifuged at $4^{\circ} \mathrm{C}$ within $30 \mathrm{~min}$. Plasma was stored at $-20^{\circ} \mathrm{C}$ until analysis.

Analysis. Plasma glucose concentrations were analysed at the bedside using a Beckman analyser (Beckman Instruments, Fullerton, Calif., USA).

Hormone analyses: Plasma insulin concentrations were measured according to the principles of Albano and Ekins [21] using standards of human insulin and antibody code no. 2004. The sensitivity of the assay is approximately $3 \mathrm{pmol} / \mathrm{l}$, the intra-assay coefficient of variation is $7 \%$ at $39 \mathrm{pmol} / \mathrm{l}$ and the coefficient of inter-assay variation is $8 \%$ at $48 \mathrm{pmol} / 1$. The glucagon assay is directed against the $\mathrm{C}$-terminus of the glucagon molecule (antibody code no. 4305) and therefore measures glucagon of mainly pancreatic origin. The sensitivity is approximately $1 \mathrm{pmol} / \mathrm{l}$, and the intra-assay coefficient of variation is below $6 \%$ in the range between 10 and $25 \mathrm{pmol} / \mathrm{l}$ [22]. Plasma concentrations of GLP-1 were measured as described previously [23] against standards of synthetic GLP-1(7-36amide) (= proglucagon 78-107amide) using antiserum code no. 89390 , which can be used in a final dilution of 1:250 000 and gives the assay a detection limit below $1 \mathrm{pmol} / \mathrm{l}$. This antiserum 
is highly specific for the C-terminus of proglucagon $78-107$ amide, and therefore mainly reacts with GLP-1 of intestinal origin [23]. GIP was measured by using a C-terminally directed antibody (code no. R65), reacting $100 \%$ with human GIP, but not with so-called $8 \mathrm{kDa}$ GIP, the nature and relation of which to the synthesis and secretion of GIP is still unclear $[24,25]$. The detection limit is $5 \mathrm{pmol} / \mathrm{l}$, intra-assay coefficient of variation $9 \%$ and the inter-assay coefficient of variation $20 \%$ in the low area of the standard curve and $15 \%$ in the high area. For glucagon, GLP-1 and GIP analysis, plasma was extracted with ethanol (final concentration $70 \% \mathrm{vol} / \mathrm{vol}$ ) prior to analysis. C-peptide concentrations were measured using commercial ELISA kits (code No. K6218, Dako, Copenhagen, Denmark). The sensitivity of the assay is $17 \mathrm{pmol} / \mathrm{l}$ and the intra-assay coefficient of variation 3-6\% at 380-2700 pmol/l. The cross reactivity with intact and split proinsulins is $63-87 \%$.

Statistical analysis and calculations. All results are presented as the mean \pm SEM. The significance of differences between the infusion protocols are calculated by repeated measures ANOVA (analysis of variance) for parametric data followed by a Bonferroni test for multiple comparisons. Friedman's repeated measures ANOVA followed by Dunn's multiple comparisons test are used in the case of non-Gaussian distribution. Statistical significance is $\mathrm{p}$ less than 0.05 .

After termination of the glucose infusion the glucose assimilation constant, $\mathrm{K}$, was determined for each subject from the linear part of the slope of the logarithmically transformed plasma glucose concentrations.

\section{Results}

GLP-1 concentrations are shown in Figure 2 (upper panel). In the protocol with GLP-1 infusion, basal GLP-1 concentrations increased steeply from a mean of $8 \pm 1 \mathrm{pmol} / \mathrm{l}$ to $61 \pm 5 \mathrm{pmol} / \mathrm{l}$ after $15 \mathrm{~min}$ of GLP-1 infusion and to a maximum of $71 \pm 5 \mathrm{pmol} / 1$ at $60 \mathrm{~min}$. Plasma GLP-1 concentrations then decreased due to the hourly stepwise decrease of the infusion rate and almost reached preinfusion levels at the end of the experiment. Basal plasma GLP-1 concentrations $(9 \pm 1 \mathrm{pmol} / \mathrm{l}$ with glucose alone, $7 \pm 1$ $\mathrm{pmol} / \mathrm{l}$ with low GIP and $11 \pm 2 \mathrm{pmol} / \mathrm{l}$ with high GIP) decreased significantly during the $30 \mathrm{~min}$ glucose infusion to $6 \pm 1 \mathrm{pmol}, 5 \pm 1 \mathrm{pmol} / \mathrm{l}$, and $7 \pm 1$ $\mathrm{pmol} / \mathrm{l}$, respectively, but at the end of the experiment returned towards basal levels.

GIP concentrations are shown in Figure 2 (lower panel). Basal GIP, which did not differ significantly between the four protocols, increased steeply in the two GIP protocols to peak values at $60 \mathrm{~min}$ of $137 \pm 8$ $\mathrm{pmol} / \mathrm{l}$ with low GIP and $372 \pm 34 \mathrm{pmol} / \mathrm{l}$ with high GIP. Thereafter, GIP decreased with time, although not quite reaching basal levels by the end of the experiments. In the GLP-1 protocol, basal GIP decreased significantly with time in the period $0-60 \mathrm{~min}$, and then increased, whereas in the protocol with glucose infusion alone no significant change occurred.

Infusion of glucose alone or combined with insulinotropic gut hormones increased insulin concentra-
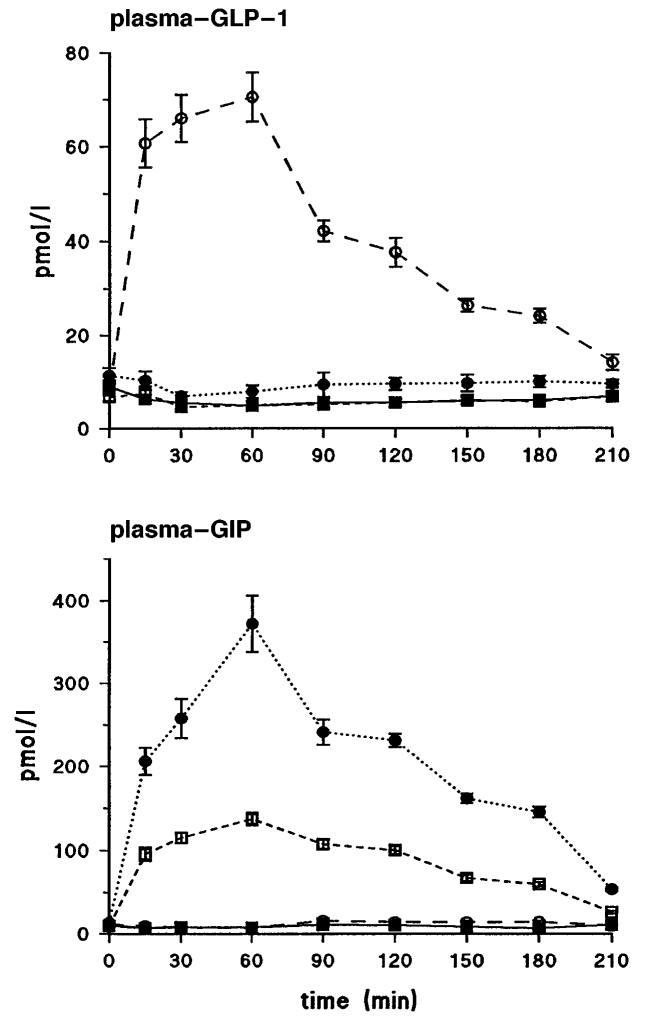

Fig. 2. Plasma GLP-1 (upper panel) and GIP (lower panel) concentrations with glucose infusion alone (- - -), low GIP infusion $(--\square--)$, high GIP infusion (......), and GLP-1 infusion $\left(--\mathrm{O}_{-}-\right)$. Mean \pm SEM

tions (Fig.3) from $51 \pm 5 \mathrm{pmol} / \mathrm{l}$ (glucose alone), $58 \pm 6 \mathrm{pmol} / \mathrm{l}$ (GLP-1), $48 \pm 5 \mathrm{pmol} / \mathrm{l}$ (low GIP) and $53 \pm 7 \mathrm{pmol} / \mathrm{l}$ (high GIP) (NS) to peak values at $30 \mathrm{~min}$ (end of glucose infusion) of $234 \pm 36 \mathrm{pmol} / \mathrm{l}$ (glucose alone), $2323 \pm 212$ (GLP-1), $1103 \pm 293$ $\mathrm{pmol} / \mathrm{l}$ (low GIP), and $1460 \pm 338 \mathrm{pmol} / \mathrm{l}$ (high GIP) $(p<0.0001$ for ANOVA comparison of all four protocols; upon post hoc Bonferroni analysis only low and high GIP peak values were NS). Insulin concentrations decreased rapidly after termination of the glucose infusion and at 60 min no significant differences between protocols were present.

As illustrated in Figure 3, C-peptide concentrations increased from similar basal to $30 \mathrm{~min}$ values of $776 \pm 78$ (glucose alone), $2492 \pm 382$ (GLP-1), $1944 \pm 477$ (low GIP), and $2642 \pm 425 \mathrm{pmol} / 1$ (high GIP) $(p<0.0001$ for ANOVA comparison of all four protocols; $p<0.001$ for comparison of hormones compared with glucose alone; peak values obtained with the different hormones were NS). Incremental or total area under curves were similar during hormone infusions, but smaller for glucose alone compared with high GIP and GLP-1 $(p<0.01)$.

Glucagon concentrations (Fig. 3 ) in the four protocols did not differ significantly in the basal state (or after termination of the glucose infusion), nor did the individual decreases in glucagon concentration 

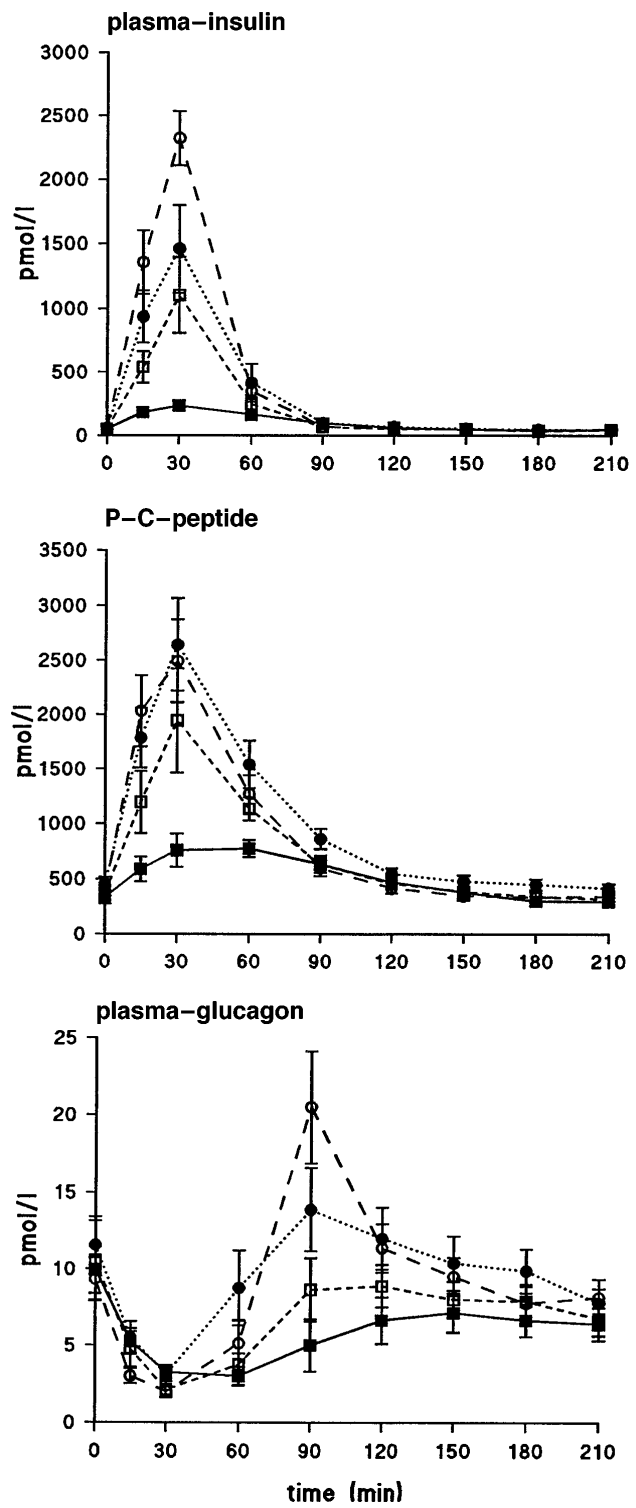

Fig.3. Plasma insulin (upper panel), C-peptide (middle panel), and glucagon (lower panel) concentrations with glucose infusion alone (-口-), low GIP infusion $(--\square--)$, high GIP infusion $(\ldots \circ \ldots)$, and GLP-1 infusion $\left(--O_{--}\right)$. Mean \pm SEM

differ between the protocols during the $30 \mathrm{~min}$ glucose infusion. The $60 \mathrm{~min}$ glucagon concentrations were $3.0 \pm 0.6 \mathrm{pmol} / \mathrm{l}$ (glucose alone), $5.1 \pm 1.5 \mathrm{pmol} / 1$ (GLP-1), $3.8 \pm 0.7 \mathrm{pmol} / \mathrm{l}$ (low GIP), and $8.8 \pm 2.5$ $\mathrm{pmol} / \mathrm{l}(p<0.048$ for comparison of all four protocols; NS by Bonferroni comparisons; although by a Student's $t$-test high GIP was significantly different from glucose alone). In the GLP-1 protocol, the initial decrease was followed by a significant increase above basal level at $90 \mathrm{~min}$. Also, at this time glucagon concentrations were higher during high GIP and GLP-1 infusions than during glucose alone.

During the 30 min glucose infusion plasma glucose concentrations (Fig. 4) increased from a basal level of $5.3 \pm 0.1$ (glucose alone), $5.4 \pm 0.1$ (GLP-1), $5.4 \pm 0.1$

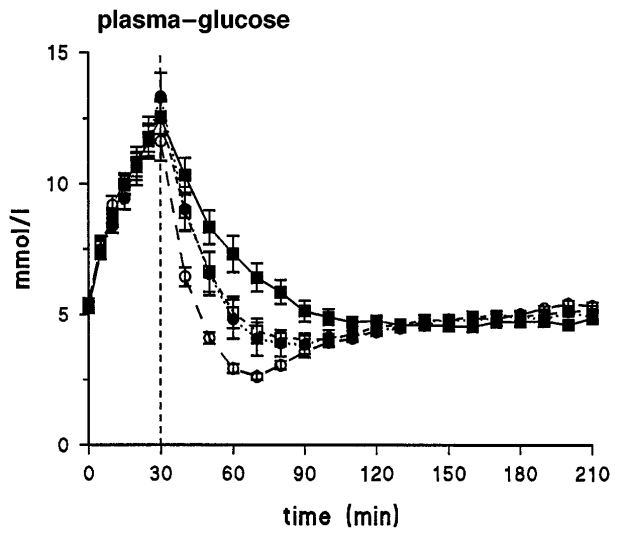

Fig. 4. Plasma glucose concentrations with glucose infusion alone (-口-), low GIP infusion (-- $\square--$ ), high GIP infusion $(\ldots \odot \ldots)$, and GLP-1 infusion (--O--). Mean \pm SEM

(low GIP) and $5.3 \pm 0.1 \mathrm{mmol} / \mathrm{l}$ (high GIP) (NS) to $12.5 \pm 0.6,11.6 \pm 0.8,12.6 \pm 0.7$ and $13.3 \pm 0.9 \mathrm{mmol} / \mathrm{l}$, respectively ( $p=0.037$ for comparison of all four protocols; peak values obtained during GLP-1 infusion were significantly lower than those obtained during high GIP infusion). The accumulated glucose infusions amounted to $33.4 \pm 1.3 \mathrm{~g}$ glucose (GLP-1), $28.0 \pm 1.2 \mathrm{~g}$ glucose (low GIP) and $38.4 \pm 3.5 \mathrm{~g}$ glucose (high GIP) (significantly different for low GIP vs high GIP, NS for low GIP vs GLP-1 and GLP-1 vs high GIP). After termination of glucose infusion plasma glucose concentrations decreased at significantly different rates. Glucose assimilation constants, K, calculated from the individual glucose curves after termination of glucose infusion were $1.6 \pm 0.2$ (glucose alone), $5.2 \pm 0.4$ (GLP-1), $3.4 \pm 0.4$ (low GIP), and $3.7 \pm 0.4 \%$ per min (high GIP) $(p<0.0001$ for comparison of all four protocols; upon post hoc Bonferroni test only high GIP compared with low GIP did not differ significantly). During the subsequent 150 min period the median and range of the lowest plasma glucose concentrations were 4.5 (3.5-4.9) with glucose alone, 2.4 (1.9-2.8) with GLP-1 (significantly lower than in all other protocols), 3.7 (2.6-4.0) with low GIP (significantly lower than glucose infusion alone) and 3.3 (2.1-4.2) with high GIP (significantly lower than glucose infusion alone). Biochemical hypoglycaemia with plasma glucose concentrations below $2.5 \mathrm{mmol} / \mathrm{l}$ developed in seven subjects with GLP-1, one with high GIP, and none with low GIP infusion. In the GLP-1 protocol, all subjects experienced hypoglycaemic signs and symptoms consisting of paleness, fatigue and muscular weakness. Some, in addition, were in a confused state and showed profuse sweating and tremor. The one person with plasma glucose below $2.5 \mathrm{mmol} / \mathrm{l}$ in the high GIP protocol had similar symptoms of hypoglycaemia. None of the subjects had hypoglycaemic symptoms in the low GIP protocol. 


\section{Discussion}

Our study has shown that GLP-1 alone, but not GIP alone, can induce reactive hypoglycaemia, indicating that the exaggerated GLP-1 response to nutrients in patients with accelerated gastric emptying may be responsible for their high incidence of postprandial reactive hypoglycaemia.

The hormone infusion rates (GLP-1 and low GIP) were chosen to mimic as closely as possible the concentrations seen in patients with the dumping syndrome. The highly specific GLP-1 and GIP assays used by us have recently been used for analysing plasma concentrations in such patients. In 15 patients investigated with an oral glucose tolerance test plasma concentrations of GLP-1 and GIP increased from basal levels of $9 \pm 1$ (GLP-1) and $17 \pm 2$ (GIP) to $89 \pm 17$ (GLP-1) and $103 \pm 14 \mathrm{pmol} / \mathrm{l}$ (GIP) at $20 \mathrm{~min}$ (unpublished studies by J. Miholic and J. J. Holst). Values at $60 \mathrm{~min}$ were $59 \pm 8$ (GLP-1) and $54 \pm 5 \mathrm{pmol} / \mathrm{l}$ (GIP), respectively. Compared with 10 control subjects peak GIP values were raised by $87 \%(p<0.01)$ and GLP- 1 by more than $300 \%(p<0.001)$, whereas areas under the curves were similar for GIP and raised fourfold for GLP-1. The plasma profiles for GLP-1 and GIP obtained were, therefore, very similar to those of the patients. For GLP-1, higher concentrations have been found previously in patients with dumping syndrome [11], but we suspect this was because of less specific analytical techniques. Moreover, with a higher infusion rate, even more pronounced effects on insulin and blood glucose might have been observed [26]. In previous studies of postgastrectomy patients GIP responses to a test meal or oral glucose were either similar [13] or raised $[14,15]$ compared with control subjects or with our results. Again, part of the differences could be because of the assays used. Presumably, therefore, the GLP-1 and GIP (low rate) levels obtained here cover adequately the levels observed in patients with the dumping syndrome. In such patients, however, GLP-1 and GIP are being secreted concomitantly during meal or glucose stimulation, and their insulinotropic actions are additive [27]. Furthermore, recent studies have shown that GIP and GLP-1 activate the same intracellular machinery in human beta cells [28]. The insulin responses in the patients, therefore, are due to the combined actions of the two insulinotropic hormones. Our original protocol included a combined infusion of GLP-1 and GIP. Because of the pronounced hypoglycaemic effect of GLP-1 alone, we did not carry out these experiments. Addition of GIP to the GLP-1 infusion would be predicted to aggravate the hypoglycaemic response, even if the hypoglycaemic effect of the low rate GIP infusion was small.

GLP-1 treatment was associated with manifest hypoglycaemia. Both the low and the high rate GIP infusions caused faster and more pronounced decreases in blood glucose than glucose alone, but there was lit- tle dose-effect (in agreement with the rather similar insulin responses) and the median blood glucose concentration for the high rate infusion did not fall below $3.3 \mathrm{mmol} / \mathrm{l}$. The higher peripheral insulin concentrations obtained with GLP-1 could explain its stronger hypoglycaemic effect, but during the high GIP infusions similar C-peptide responses were obtained allowing a comparison of the two hormones at equal rates of insulin secretion. Part of the additional hypoglycaemic effect of GLP-1 could, therefore, be due to its effect on glucagon secretion. Differences were observed with respect to glucagon responses. Glucagon concentrations were similarly suppressed in all four protocols during the glucose infusion, but increased at 60 min to almost basal levels in the high GIP protocol. A tendency to an increase was also noted in the GLP-1 protocol, but less so than in the high GIP protocol, in spite of significantly lower blood glucose concentrations (below $3 \mathrm{mmol} / \mathrm{l}$ ). Presumably the glucagonostatic effect of GLP-1 is reponsible for this [29]. Thus, an inhibited secretion of glucagon could have contributed to the hypoglycaemic effects of GLP-1. At $90 \mathrm{~min}$, after the glucose nadir in the GLP-1 protocol (occurring at a mean of $71 \mathrm{~min}$ ), however, glucagon concentrations increased clearly exceeding the basal levels. Possibly, at this time, the stimulatory effects of hypoglycaemia surpass the inhibitory effect of GLP-1. To illustrate the interactions of glucose and GLP-1 on glucagon secretion, glucagon concentrations were plotted against plasma glucose: in Figure 5A 60 min glucagon values against 60 min glucose values; and in Figure 5B 90 min glucagon values against nadir of plasma glucose within the 60-90 min period. Plasma glucagon concentrations at 90 min showed a curvilinear co-variation with plasma glucose when related to the glucose nadir. This relation was the same in the GLP-1 protocol as in the other protocols, indicating that in relation to hypoglycaemia, GLP-1 did not appreciably inhibit glucagon secretion. At $60 \mathrm{~min}$, however, all except one of the glucagon values obtained in the GLP-1 protocol were clearly displaced below the curve relating glucagon concentrations to plasma glucose in the other 3 protocols, illustrating the GLP-1 mediated inhibition of glucagon secretion at this time. Thus, in spite of the pronounced glucagonostatic effect of GLP-1 at higher glucose concentrations (including the hyperglycaemic levels of patients with diabetes mellitus), GLP-1 does not abolish the counterregulatory secretion of glucagon at hypoglycaemic levels.

The mechanism whereby GLP-1 inhibits glucagon secretion is not clarified. If a paracrine inhibition of glucagon secretion by insulin is involved, the changes in glucagon concentrations mainly reflect the insulinotropic effect of GLP-1. On the other hand, recent investigations seem to point to paracrine inhibition via intra-islet somatostatin secretion as the mechanism whereby GLP-1 inhibits glucagon secretion, 


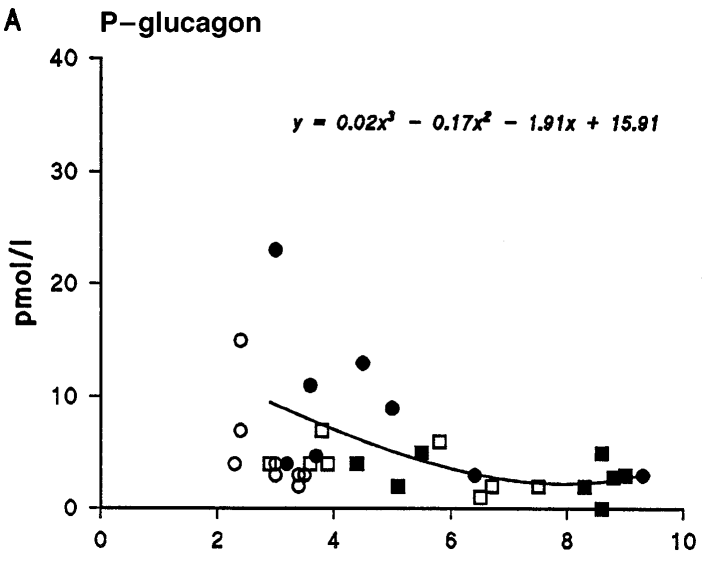

B

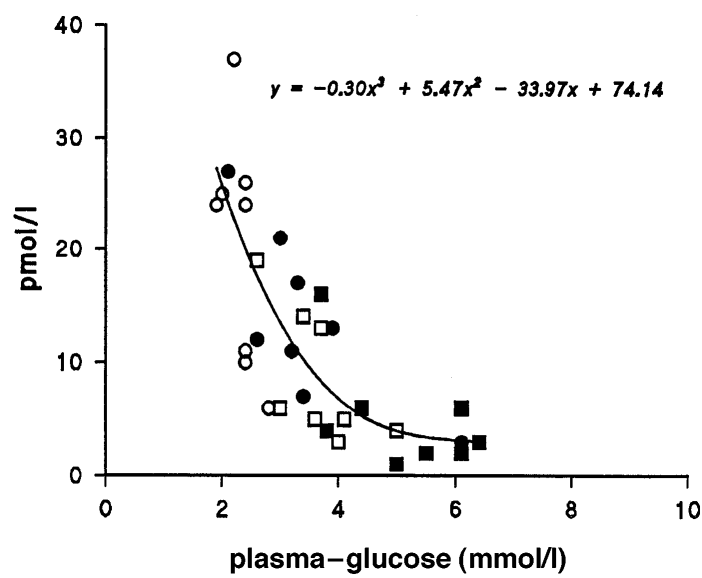

Fig. 5. Panel A shows the 60 min plasma glucagon concentrations against the 60 min plasma glucose concentrations in the protocol with glucose infusion alone $(\boldsymbol{\square})$, low GIP infusion $(\square)$, high GIP infusion (๑), and GLP-1 infusion ( $\bigcirc)$. The polynomium was fitted to the data from all protocols except the GLP-1 protocol. Panel B shows 90 min plasma glucagon concentrations against nadir of plasma glucose concentrations within the 60-90 min period

thus, indicating a more independent effect of GLP-1 on glucagon secretion [30].

As noted above, without glucose infusion, hypoglycaemia cannot be brought about by GLP-1 regardless of dose [19]. Furthermore, we have shown previously that, in humans, GLP-1 is unlikely to have direct effects on glucose production or disposal [31, 32]. Therefore, the hypoglycaemic effect of GLP-1 seems to be due, in addition to inhibition of glucagon secretion, to the prolonged effect on glucose disposal of excessive amounts of insulin released by the combined actions of GLP-1 and glucose. Thus, as glucose concentrations decrease after termination of glucose infusion, the insulinotropic effect of GLP-1 also wanes, but some time is still required to metabolise the insulin present in the circulation; the insulin effect on glucose disposal in the tissues also requires some time to subside [33]. In addition, hepatic glucose production is probably lower because of lower glucagon levels. This is clearly illustrated by the glucose dispos- al rates calculated from the plasma glucose curves after the termination of glucose infusion. The disposal rate obtained in the GLP-1 protocol exceeded those obtained in the other protocols. Therefore, plasma glucose decreased below fasting levels. According to this view and in agreement with the experimental data, the hypoglycaemic process is self-limiting. The higher peripheral plasma insulin concentrations and the identical C-peptide responses obtained with GLP-1 compared with GIP, suggest that the two hormones have different effects on hepatic or peripheral extraction of insulin or C-peptide or both, an observation which deserves further investigation.

Plasma samples were prepared from venous rather than arterialised blood. In the time interval from 15 to $45 \mathrm{~min}$ insulin concentrations and glucose disposal rates were high in the protocols with GLP-1 and GIP infusion. The glucose concentrations reported for this period are, therefore, likely to be approximately $0.5 \mathrm{mmol} / \mathrm{l}$ lower than arterialised levels [34]. In the period from $60 \mathrm{~min}$ to the end of the experiments, however, insulin concentrations were low and not significantly different. The arterio-venous glucose differences are, therefore, less pronounced and do not differ between the four protocols. Our use of venous plasma for glucose determinations is, therefore, unlikely to influence the conclusions of the study.

GLP-1 has been proposed as a possible new antidiabetic drug [35], owing to its glucose lowering effect, which is conserved in patients with Type II (non-insulin-dependent) diabetes mellitus [36,37]. Because of the glucose-dependency of its insulinotropic effect GLP-1 has been considered a safe drug. As shown in our study however, GLP-1 is capable of inducing reactive hypoglycaemia and the possibility that this can occur during treatment should therefore be considered. Because of the insulin resistance of patients with Type II diabetes this risk seems to apply to a very small number of patients.

Both GLP-1 and GIP concentrations decreased during the glucose protocols with GIP or GLP-1 infusions. For GIP, increased plasma insulin could be responsible [38] but for GLP-1 such a mechanism has not been reported so far. Possibly therefore, a negative feed-back loop to insulin secretion exists for both hormones. A regulatory role for plasma glucose alone is not supported by experimental data [39]. GIP has been reported to stimulate GLP-1 secretion in rats [40] but, in agreement with previous results [36], had no such effect in our experiments.

Acknowledgements. We thank Lene Albæk and Susanne Reimer for technical assistance. The study was supported by the Danish Diabetes Association, The Foundation of Poul \& Erna Sehested Hansen, The Danish Medical Association Research Fund, Danish Medical Research Council and the NOVO Nordisk Foundation. J. J. Holst is a member of the Biotechnology Center for Signal Peptide Research. 


\section{References}

1. Roth DA, Maede RC (1965) Hyperinsulinism-hypoglycemia in the postgastrectomy patient. Diabetes 14: 526-528

2. Shultz KT, Neelon FA, Nilsen LB, Lebovitz HE (1971) Mechanism of postgastrectomy hypoglycemia. Arch Intern Med 128: 240-246

3. Hocking MP, Vogel SB (1991) Woodward's postgastrectomy Syndromes. 2nd edn. WB Saunders Company, Philadelphia

4. Lawaetz O, Aritas Y, Blackburn AM, Ralphs DNL (1982) Gastric emptying after peptic ulcer surgery. Scand J Gastroenterol 17: $1065-1072$

5. Amdrup E, Hjorth P, Jørgensen JB (1958) Radiologic demonstration of variations in the fluid content of the small intestine during dumping attacks. Br J Radiol 31: 542-548

6. Duthie HL, McKellar NJ (1960) Radiological appearances in the post-gastrectomy dumping syndrome. Br J Radiol 33: 171-177

7. Christoffersen E, Kewenter J, Kock NG (1962) Intestinal motility during provoked dumping reaction. Acta Chir Scand 123: 405-414

8. Holdsworth CD, Turner D, McIntyre N (1969) Pathophysiology of post-gastrectomy hypoglycaemia. BMJ 4: 257-259

9. McIntyre N, Holdsworth CD, Turner DS (1965) Intestinal factors in control of insulin secretion. J Clin Endocrinol Metab 25: $1317-1324$

10. Miholic J, Ørskov C, Holst JJ, Kotzerke J, Meyer HJ (1991) Emptying of the gastric substitute, glucagon-like peptide-1 (GLP-1), and reactive hypoglycemia after total gastrectomy. Dig Dis Sci 36: 1361-1370

11. Andreasen JJ, Ørskov C, Holst JJ (1994) Secretion of glucagon-like peptide-1 and reactive hypoglycemia after partial gastrectomy. Digestion 55: 221-228

12. Kreymann B, Ghatei MA, Williams G, Bloom SR (1987) Glucagon-like peptide-1 7-36: a physiologic incretin in man. Lancet ii:1300-1304

13. Lawaetz O, Blackburn AM, Bloom SR, Aritas Y, Ralphs DNL (1983) Gut hormone profile and gastric emptying in the dumping syndrome. Scand J Gastroenterol 18: 73-80

14. Schattenmann G, Ebert R, Siewert R, Creutzfeldt W (1984) Different response of gastric inhibitory polypeptide to glucose and fat from duodenum and jejunum. Gastroenterol 19: 260-266

15. Jorde R, Schulz TB, Burhol PG, Schulz LB (1981) The response of plasma gastric-inhibitory polypeptide (GIP) to slow and fast glucose ingestion in Billroth II resected patients and normal controls. Regul Pept 2: 391-239

16. Thromford NR, Sirinek KR, Crockett SE, Mazzaferri EL, Cataland S (1974) Gastric inhibitory polypeptide. Arch Surg 109: $177-182$

17. Miholic J, Ørskov C, Holst JJ, Kotzerke J, Pichlmayr R (1993) Postprandial release of glucagon-like peptide-1, pancreatic glucagon, and insulin after esophageal resection. Digestion 54: 73-78

18. Schirra J, Katschinski M, Weidmann C et al. (1996) Gastric emptying and release of incretin hormones after glucose ingestion in humans. J Clin Invest 97: 92-103

19. Qualmann C, Nauck MA, Holst JJ, Ørskov C, Creutzfeldt W (1995) Insulinotropic actions of intravenous glucagon-like peptide-1 (GLP-1) [7-36 amide] in the fasting state in healthy subjects. Acta Diabetol 32: 13-16

20. Nauck M, Schmidt WE, Ebert R et al. (1989) Insulinotropic properties of synthetic human gastic inhibitory polypeptide in man: interactions with glucose, phenylalanine, and cholecystokinin-8. J Clin Endocrinol Metab 69: 654-662

21. Albano JDM, Ekins RP, Maritz G, Turner RC (1972) A sensitive, precise radioimmunoassay of serum insulin relying on charcoal separation of bound and free hormone moieties. Acta Endocrinol 70: 487-509

22. Ørskov C, Jeppesen J, Madsbad S, Holst JJ (1991) Proglucagon products in plasma from non-insulin dependent diabetics and non-diabetic controls in the fasting state and following oral glucose and intravenous arginine. J Clin Invest 87: 415-423

23. Ørskov C, Rabenhøj L, Kofod H, Wettergren A, Holst JJ (1994) Tissue and plasma concentrations of amidated and glycine-extended glucagon-like peptide-1 in humans. Diabetes 43: 535-539

24. Krarup T, Madsbad S, Moody AJ et al. (1983) Diminished immunoreactive gastric inhibitory polypeptide response to a meal in newly diagnosed type I (insulin-dependent) diabetics. J Clin Endocrinol Metab 56: 1306-1312

25. Krarup T, Holst JJ (1984) The heterogeneity of gastric inhibitory polypeptide in porcine and human gastrointestinal mucosa evaluated with five different antisera. Regul Pept 9: 35-46

26. Ritzel R, Ørskov C, Holst JJ, Nauck MA (1995) Pharmacokinetic, insulinotropic, and glucagonostatic properties of GLP-1 [7-36 amide] after subcutaneous injection in healthy volunteers. Dose-response-relationships. Diabetologia 38: 720-725

27. Nauck MA, Bartels E, Ørskov C, Ebert R, Creutzfeldt W (1993) Additive insulinotropic effects of exogenous synthetic human gastric inhibitory polypeptide and glucagon-like peptide-1 (7-36) amide infused at near-physiological insulinotropic and glucose concentrations. J Clin Endocrinol Metab 76: 912-917

28. Gromada J, Bokvist K, Ding W, Holst JJ, Nielsen JH, Rorsman P (1998) Glucagon-like Peptide-1(7-36) amide stimulates exocytosis in human pancreatic $\beta$-cells by both proximal and distal regulatory steps in the stimulus-secretion coupling. Diabetes 47: 57-65

29. Ørskov C (1992) Glucagon-like peptide-1, a new hormone of the entero-insular axis. Diabetologia 35: 701-711

30. Gromada J, Holst JJ, Rorsman P (1998) Cellular regulation of islet hormone secretion by the incretin hormone glucagon-like peptide-1. Eur J Physiol 435: 583-594

31. Toft-Nielsen M, Madsbad S, Holst JJ (1996) The effect of glucagon-like peptide-1 (GLP-1) on glucose elimination in healthy subjects depends on the pancreatic glucoregulatory hormones. Diabetes 45: 552-556

32. Ørskov L, Holst JJ, Møller J et al. (1996) GLP-1 does not acutely affect insulin sensitivity in healthy man. Diabetologia 39: 1227-1232

33. Prager P, Wallace P, Olefsky JM (1986) In vivo kinetics of insulin action on peripheral glucose disposal and hepatic glucose output in normal and obese subjects. J Clin Invest 78: 472-481

34. Krarup T, Nürnberg B, Mikkelsen K, Astrup A, Madsbad S, Holst JJ (1990) How arterialized is blood from a heated superficial vein ? Diabetes 39 [Suppl 1] 88A (Abstract)

35. Gutniak M, Ørskov C, Holst JJ, Ahrén B, Efendic S (1992) Antidiabetogenic effect of glucagon-like peptide-1 (7-36) amide in normal subjects and patients with diabetes mellitus. N Engl J Med 236: 1316-1322

36. Nauck MA, Heimesaat MM, Ørskov C, Holst JJ, Ebert R, Creutzfeldt W (1993) Preserved incretin activity of glucagonlike peptide-1 [7-36 amide] but not of synthetic human gastric inhibitory polypeptide in patients with Type- 2 diabetes mellitus. J Clin Invest 91: 301-307

37. Nauck MA, Kleine N, Holst JJ, Willms B, Creutzfeldt W (1993) Normalization of fasting hyperglycaemia by exogenous glucagon-like peptide-1(7-36 amide) in Type 2 (non-insulindependent) diabetic patients. Diabetologia 36: 741-744

38. Creutzfeldt W, Talaulicar M, Ebert R, Willms B (1980) Inhibition of gastric inhibitory polypeptide (GIP) release by insulin and glucose in juvenile diabetes. Diabetes 29: 140-145

39. Hermann-Rinke C, Vöge A, Hess M, Göke B (1995) Regulation of glucagon-like peptide-1 secretion from rat ileum by neurotransmitters and peptides. J Endocrinol 147: 25-31

40. Roberge JN, Brubaker PL (1993) Regulation of proglucagonderived peptide secretion by glucose-dependent insulinotropic peptide in a novel enteroendocrine loop. Endocrinology 133: 233-240 